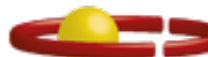 \\ UnC=UE \\ Centro Universitárı de Brasílıa \\ CENTRO UNIVERSITÁRIO DE BRASÍLIA - UnICEUB \\ PROGRAMA DE INICIAÇÃO CIENTÍFICA
}

GABRIELA AGUIAR GENGNAGEL

Amplitude de Movimento de Dorsiflexão e a Força de Reação do Solo

como fatores de risco de Lesões em Membros Inferiores em atletas da Ginástica Artística Feminina

BRASÍLIA

2020 


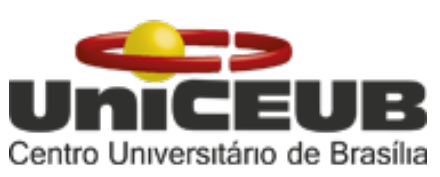

GABRIELA AGUIAR GENGNAGEL

Amplitude de Movimento de Dorsiflexão e a Força de Reação do Solo como fatores de risco de Lesões em Membros Inferiores em atletas da Ginástica Artística Feminina

Relatório final de pesquisa de Iniciação Científica apresentado à Assessoria de Pós-Graduação e Pesquisa pela Faculdade de Ciências da Educação e Saúde FACES

Orientação: Renata Aparecida Elias Dantas

\section{BRASÍLIA}




\section{DEDICATÓRIA}

Dedico este trabalho à toda comunidade ginástica, acadêmica e esportiva, e a toda minha família que desde sempre me apoiou e me acompanhou durante todo o processo. Ao meu pai Adriano Luís Gengnagel, que foi o primeiro a me apoiar a entrar para o curso de Educação Física e segue fazendo tudo o que pode para me incentivar, também à minha mãe Enelide Paulina de Oliveira Aguiar, que esteve ao meu lado sempre que precisei e continua me dando todo o suporte, e ao meu namorado Marcos Vinicius da Silva Boitrago, que me incentivou e me ajudou durante todo o período de pesquisa, eu amo vocês. 


\section{AGRADECIMENTOS}

Em tudo dai graças, porque esta é a vontade de Deus em Cristo Jesus para convosco (1Tes. 5:18). Agradeço primeiramente a Deus por permitir que eu crescesse no ambiente da ginástica artística, e por ter colocado pessoas maravilhosas no meu caminho, desde o primeiro semestre até o final deste ciclo. Agradeço também minha orientadora $\mathrm{Dr}^{\mathrm{a}}$. Renata Aparecida Elias Dantas por ter aceitado fazer parte deste projeto e ter acreditado na nossa capacidade de desenvolvê-lo juntas.

Agradeço a minha querida amiga e professora Ma. Bruna Travassos Benck que desde a primeira tentativa de aprovação deste projeto me direcionou com muito carinho ao tema escolhido, além de ter me ajudado com as correções foi uma grande referência para que eu seguisse nesta área. Agradeço também aos meus ex-técnicos, pais de consideração e atuais colegas de trabalho, Carlos Augusto Bezerra e Tatiana Biagini, que além de me oportunizarem utilizar as atletas do Setor Leste, sempre foram meus maiores apoiadores para seguir neste curso maravilhoso que é o de Educação Física, obrigada por terem feito eu me apaixonar pelo que faço.

Deixo aqui também meus agradecimentos aos meus amigos e professores Me. Felipe Alves Machado por ter apoiado este projeto, colaborando com os materiais utilizados para o estudo, também ao Me. Achilles Khaluf Soares por ter nos orientado quanto à análise estatística, e ao meu grande amigo e mestre Anderson Dornelas, que sempre me cedeu total apoio e incentivo até que este projeto fosse concretizado. Agradeço a todas as ginastas que aceitaram fazer parte deste estudo, e aos pais que concordaram e confiaram neste projeto.

Deixo aqui um agradecimento especial para a equipe da assessoria de iniciação científica em especial para a Olívia e a Clara que sempre estiveram à disposição para tirar todas as dúvidas a respeito do PIC e tornar toda essa caminhada bem mais fácil. Muito obrigado a todos vocês!!! 
"A grandeza de um ser humano não está no quanto ele sabe, mas no quanto tem consciência que não sabe" (Augusto Cury). 


\title{
Amplitude de Movimento de Dorsiflexão e a Força de Reação do Solo como fatores de risco de Lesões em Membros Inferiores em atletas da Ginástica Artística Feminina
}

\author{
Gabriela Aguiar Gengnagel - UniCEUB, PIC Institucional, aluno bolsista \\ gengnagelga@gmail.com
}

\author{
Renata Aparecida Elias Dantas - UniCEUB, professora orientadora \\ profrenataelias@gmail.com
}

A Ginástica Artística (GA) é um esporte admirado por inúmeros telespectadores, devido à suas diversas acrobacias e saltos que aparentam grande grau de dificuldade para a execução e permite que os praticantes estejam constantemente desafiando as leis da física. Embora seja um esporte precoce, iniciado ainda na infância, a GA possui (assim como todos os esportes) um índice lesivo, sendo este, maior entre as mulheres com ênfase nos membros inferiores. Dentre as regiões anatômicas mais acometidas, estão tornozelo e joelho. Fatores de risco como uso excessivo das articulações, força de reação do solo e baixa amplitude de movimento de dorsiflexão podem estar relacionados a lesões ainda em atletas jovens. Diante do exposto, o objetivo deste estudo foi analisar as variáveis de dorsiflexão de tornozelo e força de reação do solo e relacioná-los como fatores de risco de lesões em membros inferiores para atletas das categorias pré-infantil, infantil e juvenil da Ginástica Artística Feminina (GAF). Foram realizadas coletas de dados antropométricos, de força de reação do solo e de amplitude de movimento de dorsiflexão com 23 ginastas, no Centro de Iniciação Desportiva - Setor Leste. Trata-se de um estudo transversal de análise descritiva. Os dados obtidos nesta pesquisa, indicaram uma possível propensão das atletas a desenvolverem lesões nas articulações do joelho e tornozelo, uma vez que, os resultados demonstraram que $25 \%$ sentem ou já sentiram dor no tornozelo e $54 \%$ relataram sentir ou já tiveram episódio de dor e/ou lesão no joelho. Além disso, estas articulações estão mais vulneráveis, pois as atletas que apresentaram menor grau de Amplitude de Movimento de Dorsiflexão (27\%), apresentaram maior Força de Reação do Solo. Concluiu-se por meio deste, que a relação entre baixa amplitude de movimento de dorsiflexão e alta força de reação do solo podem ser consideradas fatores de risco de lesões em membros inferiores e / ou explicar possíveis traumas e lesões já sofridos no histórico das atletas, todavia ainda são poucos os estudos sobre o tema, sendo necessário pesquisas mais aprofundadas para uma melhor precisão dos resultados e conclusões.

Palavras-chave: Ginástica Artística. Lesões. Membros Inferiores. 


\section{SUMÁRIO}

1. INTRODUÇÃO ................................................................... 1

2. OBJETIVOS ...................................................................... 4

3. FUNDAMENTAÇÃO TEÓRICA .............................................. 5

4. MATERIAIS E MÉTODOS ……......................................... 8

4.1 Aspectos Éticos e Registro do Procedimento ...................... 8

4.2 Amostra .................................................................... 9

4.3 Critérios de inclusão e exclusão ........................................ 9

4.3 Procedimentos experimentais ........................................... 9

4.4 4.5Dados Antropométricos ………………………........ 10

4.5 Avaliação de ADM de dorsiflexão (lunge test) .................. 11

4.6 Avaliação da Força de Reação do Solo (drop jump) .......... 12

4.7 Análise estatística .......................................................... 13

4.8 Protocolo experimental ................................................. 13

5. Resultados ................................................................... 14

6. Discussão .................................................................. 15

7. Conclusão ....................................................................... 16

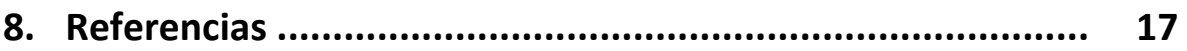

9. Anexo A …….............................................................. 21

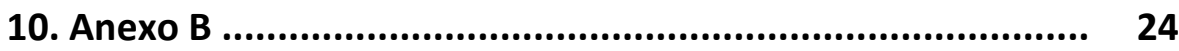

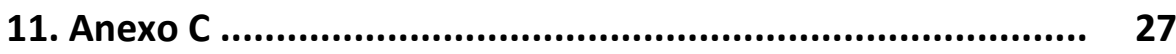

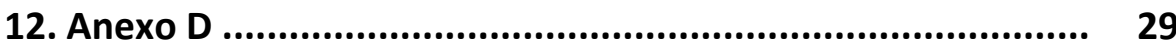




\section{INTRODUÇÃO}

A Ginástica Artística (GA) é um esporte admirado por inúmeros telespectadores devido à sua quantidade de acrobacias e saltos sobre aparelhos que aparentam grande grau de dificuldade. Os ginastas estão desafiando constantemente as leis da física, tentando alcançar e ultrapassar os limites do seu corpo e dos aparelhos, criando movimentos cada vez mais audaciosos e complexos (NUNOMURA, 2002).

Com a evolução do esporte, o aumento de praticantes dentro da GA foi bastante numeroso, e por consequência a elevação do grau de dificuldade dos exercícios e a maior excelência na execução de elementos passou a ser ainda mais exigida pelo código de pontuação, colaborando para uma elevação do risco de lesões (HOSHI, et al., 2008).

É possível observar por meio da literatura, que a incidência de lesão em ginastas do sexo feminino é maior nos membros inferiores $(54,1-70,2 \%)$ do que nos membros superiores $(17,1-50 \%)$, e destes as regiões anatômicas mais afetadas são joelho e tornozelo (CAINE; NASSAR, 2005).

Hoshi et al. (2008) relatou através de um estudo epidemiológico feito com ginastas brasileiros, que os homens apresentaram $58,82 \%$ de suas lesões em membros superiores, enquanto as mulheres tiveram $61,76 \%$ de suas lesões acometidas nos membros inferiores. Ainda segundo a autora, dentro da ginástica artística feminina (GAF) os aparelhos com predominância de saltos (Salto sobre a mesa e Solo) são os que registram maior incidência de lesões.

Como efeito da elevada complexidade de movimentos técnicos e pelo alto grau de habilidade motora que exige esta modalidade, é comum que as ginastas iniciem sua prática esportiva por volta dos 5 e 6 anos de idade. Quando completam seus 12 anos, passam a ter uma carga de treino de 20 a 40 horas semanais visando atingir seu pico de forma aos 16 e 17 anos (AMARAL et al., 2006).

Como dito, os praticantes deste esporte iniciam a sua especialização esportiva anterior à maioria dos atletas de outras modalidades, tal precocidade tem sido justificada pela forte relação entre o sucesso na modalidade e as menores dimensões corporais do atleta (SCHAVION, 2009). Deste modo, 
desde o início de sua carreira as crianças e jovens estão expostas à situações de risco de desenvolver lesões diariamente, desde as categorias de base (SILVA, 2006; CASTIGLIA, 1995).

A GA é um esporte que exige dos atletas aterrissagens perfeitas após a execução das acrobacias, o que torna os ginastas mais sucessíveis a desenvolver lesões nos membros inferiores, uma vez que estes recebem quase toda a sobrecarga dos impactos (BENCK, 2013). A taxa elevada de lesões nos membros inferiores, uma vez que os mesmos devem absorver 14 vezes o peso do corpo inteiro afim de contabilizar a nota máxima no final da execução da atleta (XIAOFEl et al., 2017).

A pouca idade combinada à longas horas de treinamento intenso também se mostram como fatores que influenciam no aumento do risco para o desencadeamento de lesões nos jovens ginastas (DALY et al., 2001). Outra justificativa tem sido a grande quantidade de componentes técnicos exigidos pela modalidade através dos regulamentos de competição (SILVA 2006; TSUKAMOTO; NUNOMURA, 2005). Estima-se que estes fatores em conjunto são a causa da maioria das lesões dos atletas da Ginástica Artística (SANDS, 2000).

Amaral, et al. (2006), traz em seu estudo outra justificativa para o risco de lesões nos ginastas, o overuse. A necessidade de repetições de certas rotinas e séries, centenas ou milhares de vezes, até obterem consistência em seus exercícios, leva ao desgaste das articulações. Os locais anatômicos mais afetados com mais da metade dos ginastas estudados foram as articulações que compõe os membros inferiores (53,5\%), seguido dos membros superiores $(24,4 \%)$, coluna vertebral $(17,3 \%)$ e o tronco $(4,7 \%)$. Esta maior predisposição para lesões nos membros inferiores pode estar associada ao alto impacto desta modalidade, tanto nas aterrissagens quanto nas impulsões pré-acrobáticas.

A GA tem um risco potencial para o desenvolvimento de lesões, assim como qualquer outro esporte. Mas, se for bem orientada e se certas medidas preventivas forem adotadas ela pode se tornar um esporte menos lesivo (NUNOMURA, 2002). Uma boa estratégia para evitar lesões pode estar na avaliação pré-temporada do sistema musculoesquelético para detectar possíveis fatores de risco que contribuem para o desenvolvimento de lesões. Dentre os principais fatores de risco podemos citar déficits neuromusculares, 
desequilíbrios de simetria muscular e déficits biomecânicos.

Com isso, muitos estudos têm sido feitos para mostrar que a experiência esportiva e a aprendizagem correta da técnica de aterrissagem auxiliam na minimização das forças de impacto e, consequentemente, diminuem o número de lesões (MANN 2010; MARINSEK, 2010; NUNOMURA, 2002; HOFFMAN; LIEBERMANN; GUSIS, 1997). 


\section{OBJETIVOS DA PESQUISA}

\section{Objetivo Geral}

Analisar as variáveis de dorsiflexão de tornozelo e força de reação do solo e relacioná-los como fatores de risco de lesões em membros inferiores para atletas das categorias pré-infantil, infantil e juvenil da Ginástica Artística Feminina (GAF).

\section{Objetivo específico}

- Medir a amplitude do movimento de dorsiflexão e a força de reação do solo.

- Relacionar os resultados das medidas com possíveis lesões já sofridas pelas participantes do estudo.

- Confrontar os dados da pesquisa com a literatura sobre o tema. 


\section{FUNDAMENTAÇÃO TEÓRICA}

As lesões na Ginástica Artística Feminina passaram a ser mais avaliadas por inúmeros pesquisadores (HOSHI et al., 2008) em função da taxa de incidências, que cresceu muito nos últimos tempos. O objetivo dos mesmos tem sido analisar as causas e os locais anatômicos mais afetados segundo os relatos de dor das atletas.

Uma pesquisa realizada com atletas do sexo feminino da NCAA (National Collegiate Athletic Association) revelou que o membro inferior é o mais sintomático segundo as ginastas, onde tornozelo $(17.9 \%, n=75)$ e pé $(12.4 \%, n=54)$, destas, diagnosticadas com ligamento distendido $(20.3 \%, n=$ $85)$ e com distensão do músculo/tendão (18.7\%, $n=78)$. Aproximadamente $12.4 \%(n=52)$ das lesões resultou em uma perda de 3 semanas de treino. $E$ do total das 291 lesões relatadas, $41.9 \%(n=122)$ ocorreu durante o treino do aparelho solo (ZACHARY et al., 2015).

Outra pesquisa realizada com 963 ginastas de todas as modalidades (artística, rítmica e de trampolim) durante os jogos olímpicos de 2016 registrou a incidência de 84 lesões diferentes entre os atletas das quais $22 \%$ foram encontradas no tornozelo e 35\% causadas por entorse. Destes, a taxa mais elevada se encontra dentro da GAF (107 +/-35). Esta mesma pesquisa concluiu que deve haver um maior foco na prevenção de lesões na Ginástica Artística Feminina e no condicionamento de tornozelo (PASCAL et al., 2017).

No estudo de Seegmiller e Mccawt (2003), 20 estudantes do sexo feminino, com idades entre 18 e 23 anos se voluntariaram para participar de um estudo que buscou comparar as forças de reação do solo durante as aterrissagens de acrobacias entre dois grupos teste: 10 atletas de recreação e 10 atletas de alto rendimento, mensurou medidas de primeira magnitude de força de pico e tempo para descrever o perfil de força de reação do solo para cada ensaio, em alturas de plataforma de 30, 60 e $90 \mathrm{~cm}$ (altura do grupo). Os autores concluíram que o grupo das ginastas possui um maior grau de forças de reação durante as aterrissagens e que este pode sim contribuir para a incidência de lesões nos membros inferiores.

Por meio de um estudo do salto vertical, Cruz (2003) verificou que a força de aterrissagem no solo é maior que a de saída para todos os sujeitos 
analisados, todos os gráficos da plataforma de força mostraram que a exigência de força no amortecimento do salto pode atingir três vezes mais que o peso corporal do sujeito em saltos sequencias.

Um dos principais fatores que colabora para o acometimento de lesões nos membros inferiores nas ginastas são as altas cargas de impacto exercidas pelas acrobacias que exigem das atletas grande potência, altura e precisão durante a aterrissagem (MARSHALL et al., 2007). Há uma força de reação do solo que vai de 8 a 18 vezes o peso corporal no momento final da acrobacia (aterrissagem), fazendo com que o impacto sobre as articulações seja maior que a capacidade de absorção dos músculos, tornando os membros inferiores ainda mais suscetíveis para a aparição de lesões (FORKIN et al.' 1996), confirmado por SOUZA e ALMEIDA (2006), que relataram em sua pesquisa que o impacto sobre estruturas articulares é maior que a capacidade de absorção dos músculos, agredindo o tecido que as compõe.

Em uma pesquisa, Fong et al. (2011) associaram a ADM de dorsiflexão à aterrissagem e concluíram que uma maior mobilidade de tornozelo contribui para diminuição dos riscos de lesões em membros inferiores. Segundo os mesmos, a maior ADM passiva de dorsiflexão do tornozelo colabora para um maior deslocamento de flexão do joelho e menores forças de reação do solo durante a aterrissagem.

KIRIALANIS et al. (2003) revelou em uma pesquisa que ginastas femininas apresentam o tornozelo como o local anatômico mais acometido por lesões, com aproximadamente $48 \%$ destas ocorrendo no pouso e $36 \%$ durante a decolagem. Uma outra pesquisa revelou que uma amplitude de movimento reduzida de dorsiflexão de tornozelo colabora para o valgo dinâmico de joelho, que é também um fator de risco para lesões nos membros inferiores (SACCOL et al., 2018).

As aterrissagens de calcanhar-a-dedo resultaram em um menor deslocamento do plano sagital no tornozelo, joelho e quadril e elevadas forças verticais de reação no solo. O estudo que analisou esta variável avaliou a influência da posição dos pés na biomecânica da aterrissagem e concluiu que uma maior amplitude de movimento de dorsiflexão diminui as forças de reação do solo (KOVACS et al., 1999).

Decker et al. (2003) em seu estudo relataram que em comparação ao 
grupo de homens avaliados, o grupo das mulheres utilizava uma maior dorsiflexão do tornozelo para absorver energia e realizar aterrissagens com mais segurança. Ainda segundo os estudiosos, essa estratégia de pouso é benéfica e pode diminuir a carga do ligamento cruzado anterior dissipando mais energia na articulação do tornozelo ao invés de propagá-la para a articulação do joelho, diminuindo então o risco de lesões nos membros inferiores.

Um ensaio clínico foi realizado com 22 indivíduos que apresentavam déficit de dorsiflexão de tornozelo e VDJ verificou os efeitos imediatos de técnicas de mobilização de tornozelo no ganho de dorsiflexão e melhora do valgo dinâmico de joelho. Com os resultados observou-se uma melhora na mobilidade e ganho de amplitude de movimento de tornozelo, porém nenhum ganho imediato para o VDJ. Por ser apontado como um possível fator de risco para lesões em membros inferiores, o ganho de mobilidade de tornozelo foi um feito positivo visando diminuir este risco (POLICARPO, et al. 2017).

Assim, estudos que avaliaram a ADM de dorsiflexão (DECKER et al., 2003; FONG et al. 2011), força de reação do solo (CRUZ, 2003; FONG, et al., 2011; KERR, et al., 2015) demonstraram em sua literatura que estas varáveis. 


\section{MATERIAIS E MÉTODOS}

Tipo de Estudo: Trata-se de um estudo longitudinal misto de caráter descritivo e comparativo, de análise quantitativa.

\section{Aspectos Éticos e Registro do Procedimento}

Anteriormente à realização de qualquer procedimento metodológico, este Pré-Projeto será cadastrado na Plataforma Brasil para apreciação dos aspectos éticos relacionados à pesquisa envolvendo seres humanos, conforme a Resolução n ${ }^{\circ}$ 66/12 do Conselho Nacional de Saúde, Parecer n 3.481.314. Todas aquelas que forem incluídas no estudo serão voluntárias e assinarão um Termo de Consentimento Livre e Esclarecido - TCLE (Anexo A), dando ciência de que conhecem os procedimentos a serem realizados, com as possíveis complicações relacionadas e que concordam com os objetivos da pesquisa.

O presente estudo se dispõe a produzir e reunir dados e evidências científicas a fim de que sejam compartilhadas para a utilização nos indivíduos praticantes do treinamento de força buscando uma melhoria no estilo de vida saudável. Sendo assim, considerar-se-á a necessidade de serem observados os riscos potenciais à saúde e à proteção dos direitos humanos, das liberdades fundamentais e do respeito à dignidade humana na coleta, processamento, uso e armazenamento dos dados materiais biológicos humanos.

O presente projeto, não objetiva:

- Enviar para o exterior qualquer material biológico humano

- Armazenar material biológico no exterior

- Alterar estrutura genética de células humanas para utilização in vivo - Verificar genética comportamental

- Verificar dissociação irreversível dos dados dos sujeitos da pesquisa.

As informações obtidas neste experimento, por meio dos resultados de todos os testes, serão utilizadas exclusivamente como dados de pesquisa científica, podendo ser publicados e divulgados, sendo resguardada a identidade e privacidade dos participantes. 


\section{Amostra (Sujeitos)}

Participaram do estudo 25 atletas da Ginástica Artística Feminina (GAF) de nível competitivo estadual e/ou nacional, das categorias pré-infantil (09 e 10 anos), infantil (11 e 12 anos) e juvenil (13 a 15 anos), praticantes da modalidade há pelo menos quatro anos, representantes do CID Setor Leste, Distrito Federal.

A avaliações de ADM de Dorsiflexão e Força de Reação do Solo serão realizadas no Centro de Iniciação Desportiva - Setor Leste (SGAS 611/612, Conjunto E , SN - ASA SUL - CEP: 70200-715).

\section{Critérios de Inclusão}

Puderam participar do estudo, ginastas que cumprirem os seguintes critérios de inclusão:

- Possuir uma carga horaria mínima de treino de $12 \mathrm{~h}$ semanais;

- Ter a idade de participação em competições nas categorias pré-infantil, infantil e juvenil (no mínimo nível iniciante);

- Ter permissão dos responsáveis para participar do estudo, por meio da assinatura Termo de Consentimento Livre e Esclarecido (TCLE) e assinar o termo de assentimento.

\section{Critérios de Exclusão}

Foram excluídas do estudo, atletas que não cumprirem os critérios de inclusão e/ou que sofreram algum tipo de lesão severa que não permita à mesma a prática esportiva nos 3 meses que antecedem a coleta de dados ou durante o período da pesquisa. 


\section{Dados antropométricos}

Foi utilizada uma ficha de avaliação com dados pessoais tais como nome, idade, endereço, telefone.

Dores e histórico de lesões serão perguntadas também através de uma ficha avaliativa, onde as atletas devem assinalar o local anatômico de dor e/ou lesões já sofridas. Previamente a avaliação de força de reação do solo e dorsiflexõ de tornozelo, os indivíduos foram submetidos ao protocolo de mensurações antropométricas, composto de:

- Peso - as atletas devem estar uniformizadas com o top e o short do clube e descalças. A mensuração do peso corporal será feita por meio de uma balança mecânica da marca toledo®, com precisão de 0,1.

- Altura - as atletas devem estar uniformizadas com o top e o short do clube e descalças. a mensuração da estatura será feita por meio de uma balança mecânica da marca toledo®, com precisão de $0,1 \mathrm{~cm}$ para $\circ$ estadiômetro.

\section{Avaliação da ADM de Dorsiflexão de Tornozelo (LUNGE TEST)}

A medida de ADM de dorsiflexão de tornozelo foi realizada por meio do Medidor de Ângulo AM-2(Starrett $®)$, as atletas voluntárias foram posicionadas de pé, foram tracejadas linhas para acomodação e posicionamento do membro testado, não devendo o individuo levantar o calcâneo do solo durante a realização do teste, o inclinometro será posicionado a $15 \mathrm{~cm}$ da tuberosidade da tíbia e será solicitado que o individuo realize a dorsiflexão. Foram realizadas três medidas de cada membro e tirada e média final.

Para a avaliação do risco de lesão das voluntárias, foram determinadas três bandeiras (verde, amarela e vermelha), com base em dados normativos já descritos na literatura (KONOR et.al, 2012). A bandeira verde representa o valor ideal da avaliação, sendo considerado maior que $45^{\circ}$. A bandeira amarela compreende os valores de 36 a $45^{\circ}$ e por final a bandeira vermelha engloba todos os valores abaixo de $36^{\circ}$. Esse método de avaliação foi utilizado, pois a 
literatura apresenta uma discrepância entre os valores normativos do Lunge Test. Konor e colaboradores (2012) relatam que os valores normativos variam de 30 a 50 graus em indivíduos saudáveis.

Figura 1. Posicionamento para avaliação da ADM de dorsiflexão de tornozelo

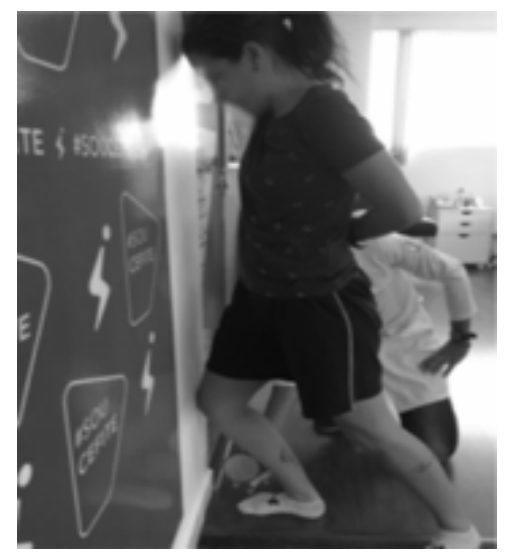

\section{Avaliação da Força de Reação no Solo (Drop Jump)}

Foi requerido às atletas, que as mesmas estivessem vestidas com uniforme de treino, top e short, para a avaliação da Força de Reação no Solo que seguiu um protocolo adaptado da plataforma Globus Brasil. Este, propôs que as voluntárias, realizassem 5 saltos pliométricos (drop jump) partindo de diferentes alturas: $20-40-60-80-100 \mathrm{~cm}$ e aterrissem da forma que preferirem, com os pés sobre a plataforma de força dupla, que avaliará ambos os membros separadamente. Para o estudo, foi utilizado apenas a altura de $60 \mathrm{~cm}$, já que um dos objetivos é confrontar a literatura, e o estudo de Seegmiller e Mccawt (2003) concluiu que esta altura tem diferença significativa para a variável de Força de Reação do Solo.

Figura 2. Plataforma Globus de salto. 


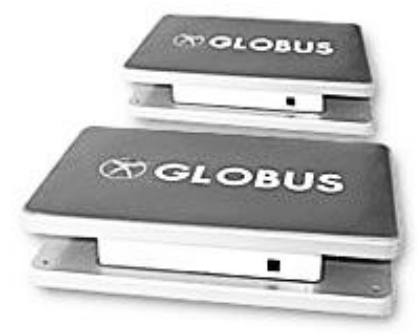

Figura 3. Caixa de madeira $60 \mathrm{~cm}$.

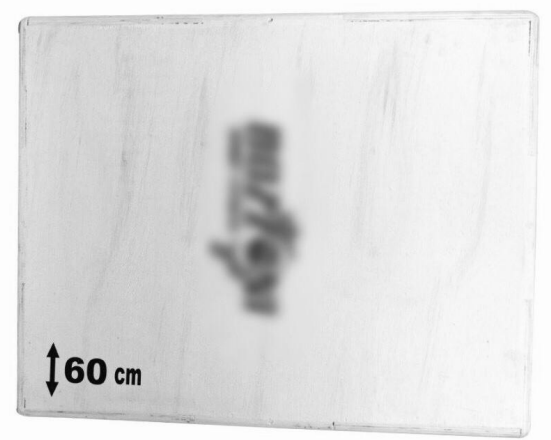

Figura 4. Execução do salto, Drop Jump.

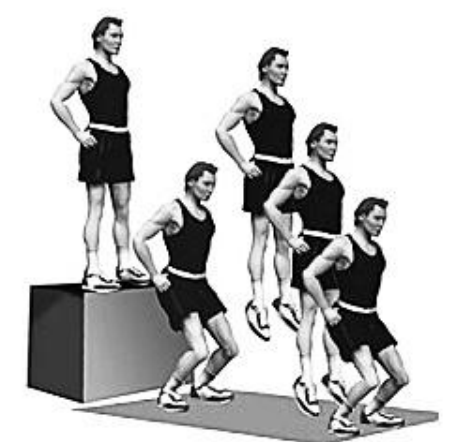




\section{Análise Estatística}

Foram realizadas análises exploratórias dos dados, com medidas descritivas de média \pm desvio-padrão para organizar os resultados. A normalidade das variáveis dependentes será confirmada pelo teste de ShapiroWilk e, com base nos resultados, foi realizado o cálculo do Coeficiente de Correlação de Pearson (r).

Todas as análises foram realizadas no programa BIOESTAT 5.0 adotando-se para os testes o nível de significância de $p \leq 0,05$.

\section{Protocolo experimental}

As atletas foram submetidas à 2 testes diferentes: ADM de Dorsiflexão de tornozelo e Drop Jump. O primeiro teste foi realizado 3 vezes e a média das mensurações será a utilizada para os resultados. O segundo utilizou para os resultados as medidas de um único salto sobre a plataforma de força. 


\section{RESULTADOS}

Os dados referentes a caracterização amostral de ambos os grupos estão presentes na tabela 1. Não houve diferença significativa $(p>0,05)$ entre os grupos na idade, na estatura, na massa corporal e no índice de massa corporal.

Tabela 1 Característica amostral dos grupos oclusão e tradicional, expostas em média \pm desvio padrão, e significância.

\begin{tabular}{lccc}
\hline Atletas & Idade (anos) & Peso (KG) & Estatura (CM) \\
\hline Média/ Desvio Padrão & $12,1 \pm 2,0$ & $12,1 \pm 2,0$ & $149,9 \pm 8,8$ \\
\hline
\end{tabular}

O gráfico 1 fornece os locais anatômicos de dor descritos pelas atletas durante a coleta de dados. Algumas ginastas alegaram sentir dor em uma ou mais articulações, destas, 6 (19\%) sentem ou já sentiram dor na lombar, 12 (54\%) sentem ou já sentiram dor no joelho e $10(27 \%)$ sentem ou já sentiram dor no tornozelo.

Gráfico 1 - Local Anatômico de Dor 
Para a avaliação de um possível risco de lesão na articulação do tornozelo das voluntárias, foram determinadas três bandeiras (verde, amarela e vermelha), com base em dados normativos já descritos na literatura (KONOR et.al, 2012). A bandeira verde representa o valor ideal da avaliação, sendo considerado maior que $45^{\circ}$. A bandeira amarela compreende os valores de 36 a $45^{\circ}$ e por final a bandeira vermelha engloba todos os valores abaixo de $36^{\circ}$. Sendo assim, o gráfico 2 descreve que das 22 atletas analisadas, $16(73 \%)$ se enquadraram na Bandeira Verde, 6 $(27 \%)$ na Bandeira Amarela e nenhuma (0) na Bandeira Vermelha. 
A tabela 2 exibe a Média e o Desvio Padrão das variáveis estudadas, Força de Reação da perna direita, e Amplitude de Movimento de Dorsiflexão do pé direito.

Tabela 2 - Média e Desvio Padrão da Força de Reação do Solo e Amplitude de Movimento de Dorsiflexão do membro inferior direito

\begin{tabular}{lllll}
\hline Atletas & Força $\mathrm{D}(\mathrm{N})$ & $\mathrm{ADM} D\left(^{\circ}\right)$ & $\mathrm{r}$ & $\mathrm{p}$ \\
& & & & \\
\hline Média/ Desvio & $711,0 \pm 196,3$ & $58,6 \pm 10,1$ & 0,42 & 0,52 \\
Padrão & & & & \\
& & & & \\
\hline
\end{tabular}

A tabela 3 exibe a Média e o Desvio Padrão das variáveis estudadas, Força de Reação da perna esquerda, e Amplitude de Movimento de Dorsiflexão do pé esquerdo.

Tabela 3 - Média e Desvio Padrão da Força de Reação do Solo e Amplitude de Movimento de Dorsiflexão do membro inferior esquerdo

\begin{tabular}{lllcc}
\hline Atletas & Força $\mathrm{E}(\mathrm{N})$ & $\mathrm{ADM} \mathrm{E}\left({ }^{\circ}\right)$ & $\mathrm{r}$ & $\mathrm{p}$ \\
& & & & \\
\hline Média/ Desvio & $707,2 \pm 239,6$ & $58,6 \pm 10,1$ & 0,30 & 0,16 \\
Padrão & & & &
\end{tabular}




\section{DISCUSSÃO}

O presente estudo teve como objetivo verificar as variáveis de dorsiflexão de tornozelo e força de reação do solo como fatores de risco de lesões em membros inferiores para atletas das categorias pré-infantil, infantil e juvenil da Ginástica Artística Feminina (GAF).

A análise completa do estudo envolveu coleta de dados clínicos como dor, e / ou lesões já sofridas pelas atletas, e ainda dados antropométricos (altura e peso), dados de Força de Reação do Solo e Amplitude de Movimento de Dorsiflexão realizadas após a entrega dos termos de assentimento e consentimento livre e esclarecido.

Diversos estudos verificam o overuse das articulações durante as aterrissagens como um dos principais fatores para desencadear lesões. Porém, o que ainda está em questão, entretanto já foi relatado, é o movimento biomecânico de aterrissagem na articulação do tornozelo.

Uma pesquisa evidenciou que os indivíduos que apresentaram a ADM de dorsiflexão maior, demonstraram menores forças de reação do solo, o que diminui o impacto sobre as articulações dos membros inferiores (FONG et al., 2011). Os resultados da presente pesquisa corroboram com este estudo, uma vez que as atletas que apresentaram menor ADM de Dorsiflexão, apresentaram maior Forçca de Reação do Solo.

Kirialanis et al. (2003) revelou em uma pesquisa que ginastas femininas apresentam o tornozelo como o local anatômico mais acometido por lesões, com aproximadamente $48 \%$ destas ocorrendo no pouso e $36 \%$ durante a decolagem. Sendo este resultado conguente com os resultados obtidos na coleta de dados, onde as atletas afirmaram já terem sofrido lesões e/ou dores nestas mesmas articulações.

É possível observar por meio da literatura, que a incidência de lesões em ginastas do sexo feminino é maior nos membros inferiores $(54,1-70,2 \%)$ do que nos membros superiores $(17,1-50 \%)$, e destes, as regiões anatômicas mais afetadas são joelho e tornozelo (CAINE; NASSAR, 2005).

Assim como nos estudos citados, o presente trabalho verificou por meio dos resultados e das varáveis em análise, o histórico de dor, a Força de Reação do Solo e a Amplitude de Movimento de Dorsiflexão em atletas da Ginástica 
Artística Feminina. Apesar da limitação do número de amostras, é possível visualizar a proximidade dos dados encontrados com os descritos na literatura. Atletas com menor ADM de dorsiflexão apresentaram maior força de reação do solo, no mesmo membro, podendo indicar um risco de lesão ou uma justificativa do histórico de dor. 


\section{CONCLUSÃO}

Os resultados apresentados descrevem que as atletas que já apresentavam histórico de dor e/ou lesão nas articulações do joelho e tornozelo estão entre as amostras classificadas na bandeira amarela, em relação a ADM de dorsiflexão, e ainda apresentaram maior força de reação do solo do mesmo lado em que esta amplitude de movimento foi menor, colaborando com a hipótese do estudo e com pesquisas anteriormente analisadas. Além disso, mesmo as ginastas classificadas na bandeira verde, quando analisados separadamente, que se enquadram em um possível risco lesivo, pois possuem um dos lados dos membros inferiores com menor ADM e maior força de reação do solo.

Outra análise que corrobora com os estudos é que ginastas mais velhas estão mais propensas a correr risco de lesões e também relataram dor e mais regiões anatômicas, uma vez que praticam a mais tempo e já demandaram mais esforços das articulações, como surgem estudos que trazem o overuse como fator de risco.

Portanto, o tema em questão deve ser mais estudado para que se tenham conclusões mais precisas sobre a relação das variáveis analisadas. Além disso, o fato de a Ginástica Artística ainda ser um esporte pouco praticado em Brasília também limita o estudo na questão de obter resultados mais significativos. 


\section{Referências}

1. AMARAL, L. SANTOS, P. FERREIRINHA, J. Caracterização do perfil lesional em ginástica artística feminina: um estudo prospectivo das ginastas portuguesas de competição ao longo de uma época desportiva. Rev. Port. Cien. Desp., v.9, n.1, p.43-51, 2006.

2. BENCK, B. T. DAVID, A C., CARMO, J C. Déficits no equilíbrio muscular em jovens atletas de ginástica feminina. Revista Brasileira de Ciências do Esporte, v.38, n.4, p.342-348, 2016.

3. BENCK, B. T. Análise biomecânica dos fatores de risco de lesões na aterrissagem de jovens atletas de ginástica feminina. Tese (Mestrado em Educação Física) - Faculdade de Educação Física da Universidade de Brasília, Brasília, 2013.

4. BITTENCOURT, N. F. N. et al. Foot and hip contributions to high frontal plane knee projection angle in athletes: a classification and regression tree approach. J Orthop Sports Phys Ther, v.42, p.996-1004, 2012.

5. BRADSHAW E. J. , HUME P. A. Biomechanical approaches to identify and quantify injury mechanisms and risk factors in women's artistic gymnastics. Sports Biomechanics, v.11, n.3, p.324-341, 2012.

6. CAINE, D. NASSAR, L. Gymnastics injuries. Med. Sport Sci., v.48, p.1858, 2005.

7. CASTIGLIA, P. T. Sports injury in children. Journal of pediatric health care, v.9, p.32-33, 1995.

8. CRUZ, E. M. Estudo do Salto Vertical: Uma análise da relação de forças aplicadas. Tese (Mestrado na área da Ciência do Desporto) Faculdade de Educação Física, Universidade Estadual de Campinas, Campinas 2003.

9. DALY, R. M. BASS, S. L. FINCH, C. F. Balancing the risk of injury to gymnasts: how effective are the conter measures? Br J Sports Med, v.35, p.8-20, 2001.

10. Decker MJ, Torry MR, Wyland DJ, Sterett WI, Steadman JR. Gender differences in lower extremity kinematics, kinetics, and energy absorption during landing. Clin Biomech (Bristol, Avon). 2003;18(7): 662-669. 
energetics in the lower extremity. Med Sci Sports Exerc. 1992;24(1):108115.

12. EDOUARD, P. et al. Gymnastics injury incidence during the 2008, 2012 and 2016 Olympic Games: analysis of prospectively collected surveillance data from 963 registred gymnasts during Olympic Games. BJ Sports Med. 2017.

13. FONG, C. M. et al. Ankle-Dorsiflexion Range of Motion and Landing Biomechanics. Journal of Athletic Training, v.46, n.1, p.5-10, 2011.

14. FORKIN, D. M., KOCZUR, C., NEWTON, R. A. Evaluation of kinesthetic déficits indicative of balance control in gymnastics with unilateral chronic ankle sprains. J. Orthop. Sports Phys. Ther., v.23, p.245-250, 1996.

15. French, D. N., Gomez, A. L., Volek, J. S., Rubin, M. R., Ratamess, N. A., Sharman, M. J., Kraemer, W. J. (2004). Longitudinal tracking of muscular power changes of NCAA division I collegiate women gymnasts. Journal of Strength and Conditioning Research, 18, 101-107.

16. HILEY, M. YEADON, M. Achieving consistente performance in a complex whole body movement: the Tkatchev on high bar. Hum. Mov. Sci., v.31, n.4, p.834-843, 2012.

17. HOFFMAN, J. R. LIEBERMANN, D. GUSIS, A. Relationship of leg strength and power to ground reaction forces in both experienced and novice jump trained personnel. Aviation, pace and enviromental medicine, v.68, n.8, p.710-714, 2011.

18. HOSHI, R. A. et al. Lesões desportivas na ginástica artística: estudos a partir de morbidade referida. Rev. Bras. Med. Esporte, v.14, n.5, 2008.

19. KERR, Z. Y. et al. Epidemiology of national collegiate athletic association women's gymnastics injuries, 2009-2010 trough 2013-2014. Journal of Athletic Training, v.50, n.8, p.870-878, 2015.

20. KIRIALANIS, P., MALLIOU, P., BENEKA, A. et al. Occurrence of acute lower limb injuries in artistic gymnasts in relation to event and exercise phase. British Journal of Sports Medicine, 37, 137-139, 2003.

21. KONOR, M.,MORTON, S., ECKERSON, J.et al. Reliability of three measures of ankle dorsiflexion range of motion. International Journal of Sports Physical Therapy. v.7(3). p.279-287, 2012.

22. KOVACS I, TIHANYI J, DEVITA P. et al.Foot placement modifies 
kinematics and kinetics during drop jumping. Med Sci Sports Exerc.;31(5):708-716, 1999.

23. MANN, L. et al. Modalidades Esportativas: Impactos, Lesões e Força de reação do solo. Revista da Educação Física/UEM, Maringá, v.21, n.3, p.533-562, 2010.

24. MARINESK, M. Basic landing characteristics and their application in artistic gymnastics. Science of Gymanstics Journal, v.2, n.2, p.59-67, 2010.

25. MARSHALL, S. W. et al. Injury incidence, mechanism and diagnosis in top-level teamgym: a prospective study conducted over one season. Scand J Med Sci Sports, v.17, n.1, p.15-9, 2007.

26. NUNOMURA, M. Lesões na ginástica artística: principais incidências e medidas preventivas. Motriz, v.18, n.1, p.21-29, 2002.

27. NUNOMURA, M.; CARRARA P. D. S.; TSUKAMOTO M. H. C. Ginástica artística e especialização precoce: cedo demais para especializar, tarde demais para ser campeão. Rev. Bras. Educ. Fís. Esporte, v.24, n.3, p.305-314, 2010.

28. POLICARPO, F. N. N. et al. Efeitos Imediatos de Duas Técnicas de Mobilização do Tornozelo na Amplitude de Dorsiflexão e Valgo Dinâmico de Joelho: Um Ensaio Clínico Aleatório. 2017. Liga de Fisioterapia Esportiva - Universidade Federal do Ceará, 2017.

29. SACCOL, M. F. et al. Valgo Dinâmico de Joelho e Redução de Dorsiflexão em Cadeia Cinética Fechada em Homens Sedentários. In: $10^{\circ}$ SALÃO INTERNACIONAL DE ENSINO, PESQUISA E EXTENSÃO - SIEPE

30. Universidade Federal do Pampa ú Santana do Livramento, 6 a 8 de novembro de 2018 .

31.SANDS, W. A. et al. Thinking sensibly about injury preventiion and safety. Science of Gymnastics Journal, v.3, n.3, p.43-58, 2010.

32. SANDS, W. A. Injury prevention in women's gymnastics. Sports Med, v.30, n.5, p.359-373, 2000.

33. SCHIAVON, L. M. Ginástica artística e história oral: a formação 
desportiva de ginastas brasileiras participantes de jogos olímpicos. Tese (Doutorado em Pedagogia do esporte) - Faculdade de Educação Física, Universidade Estadual de Campinas, Campinas, 2009.

34. SEEGMILLER, G. J. McCAWT, S. Ground Reaction Forces Among Gymnasts and Recreational Athletes in Drop Landings. Journal of Athletic Training, v.38, n.4, p.311-314, 2003.

35. SOUZA, G. M. , ALMEIDA F. S. Queixa de dor músculo-esquelética das atletas de 6 a 20 anos praticantes de ginástica artística feminina. Arq. Med. ABC, v.31, n.2, p.67-72, 2006.

36. XIAOFEI, X. et al. The influence of landing mat composition on ankle injury risk during a gymnastic landing: a biomechanical quantification. Acta of Bioengineering and Biomechanics, v.19, n.1, 2017. 


\section{ANEXO A}

Termo de Consentimento Livre e Esclarecido - TCLE

\section{"Efetividade de um Programa de Exercícios Preventivos para a diminuição de Lesões em} atletas da Ginástica Artística Feminina" Instituição dos(as) pesquisadores(as): Centro Universitário de Brasília

Pesquisador(a) responsável: Renata Aparecida Elias Dantas

Pesquisador(a) assistente [aluno(a) de graduação]: Gabriela Aguiar Gengnagel Seu filho (a) está sendo convidado(a) a participar do projeto de pesquisa acima citado. $O$ texto abaixo apresenta todas as informações necessárias sobre o que estamos fazendo. Sua colaboração neste estudo será de muita importância para nós, mas se desistir a qualquer momento, isso não lhe causará prejuízo.

O nome deste documento que o senhor(a) está lendo é Termo de Consentimento Livre e Esclarecido (TCLE).

Antes de decidir se deseja permitir que seu filho (a) possa participar (de livre e espontânea vontade) você deverá ler e compreender todo o conteúdo. Ao final, caso decida participar, você será solicitado a assiná-lo e receberá uma cópia do mesmo.

Antes de assinar, faça perguntas sobre tudo o que não tiver entendido bem. A equipe deste estudo responderá às suas perguntas a qualquer momento (antes, durante e após o estudo).

\section{Natureza e objetivos do estudo}

O objetivo específico deste estudo é demonstrar a eficácia e um programa de exercícios preventivos para a diminuição de lesões em atletas da ginástica artística feminina.

Seu filho (a) está sendo convidado(a) a participar exatamente por ser praticante e competidor(a) de ginástica.

\section{Procedimentos do estudo}

A participação de seu filho (a) consiste em ser voluntário de um procedimento que irá proporcionar benefícios a saúde tais como melhora da força, diminuição no nível e grau de dor e melhora nas técnicas de aterrissagem.

O procedimento é antes do treinamento realizar em uma avaliação física antropométrica inicialmente, seguida de avaliações musculares pré e pós intervenção. $O$ treinamento se descreve de média intensidade e médio impacto, três vezes por semana aplicados dentro de ginásio de treinamento.

Não haverá nenhuma outra forma de envolvimento ou comprometimento neste estudo. A pesquisa será realizada no Instituto Trata Joelho e Quadril (SGAS 915, Conjunto A/ Sala 359, Centro Clínico Advance Asa Sul. 


\section{Riscos e benefícios}

Este estudo possui um baixo risco que são inerentes ao procedimento de treinamento que eles(as) já estão acostumados a realizar em seus treinos, tais como por exemplo: queda. Medidas preventivas durante fadigas, dores musculares, tontura serão tomadas para minimizar qualquer risco ou incômodo, tais como ambiente e materiais adequados. Mas caso algum participante se machuque o pesquisador estará apto a ministrar os primeiros socorros , caso necessário leva (a)-lo (a) ao hospital mais próximo e arcar com as custas caso necessário. Caso esse procedimento possa gerar algum tipo de constrangimento seu filho (a) não precisa realizá-lo.

A participação de seu filho (a) poderá ajudar no maior conhecimento sobre este protocolo de treinamento e seus benefícios obtidos na prevenção de dores e lesões.

\section{Participação, recusa e direito de se retirar do estudo}

A participação de seu filho (a) é voluntária. Você não terá nenhum prejuízo se não quiser participar.

Você poderá se retirar seu(sua) filho (a) desta pesquisa a qualquer momento, bastando para isso entrar em contato com um dos pesquisadores responsáveis.

Conforme previsto pelas normas brasileiras de pesquisa com a participação de seres humanos, você não receberá nenhum tipo de compensação financeira pela sua participação neste estudo.

\section{Confidencialidade}

Os dados coletados serão manuseados somente pelos pesquisadores e não será permitido o acesso a outras pessoas.

O material com as suas informações (fichas de coleta) ficará guardado sob a responsabilidade de Gabriela Aguiar Gengnagel. Com a garantia de manutenção do sigilo e confidencialidade. Os dados e instrumentos utilizados ficarão arquivados com o(a) pesquisador(a) responsável por um período de 5 anos, e após esse tempo serão destruídos.

Os resultados deste trabalho poderão ser apresentados em encontros ou revistas científicas, entretanto, ele mostrará apenas os resultados obtidos como um todo, sem revelar seu nome, instituição a qual pertence ou qualquer informação que esteja relacionada com sua privacidade.

Se houver alguma consideração ou dúvida referente aos aspectos éticos da pesquisa, entre em contato com o Comitê de Ética em Pesquisa do Centro Universitário de Brasília - CEP/UniCEUB, que aprovou esta pesquisa, pelo telefone 3966.1511 ou pelo e-mail cep.uniceub@uniceub.br. Também entre em contato para informar ocorrências irregulares ou danosas durante a sua participação no estudo. 
$\mathrm{Eu}$, $\mathrm{RG}$

após receber a explicação completa dos objetivos do estudo e dos procedimentos envolvidos nesta pesquisa concordo voluntariamente em fazer parte deste estudo

Este Termo de Consentimento encontra-se impresso em duas vias, sendo que uma cópia será arquivada pelo pesquisador responsável, e a outra será fornecida ao senhor(a).

Brasília, de de

\section{Participante}

Renata Aparecida Elias Dantas, celular (61)981737735/telefone institucional (61) 39661511

Gabriela Aguiar Gengnagel, telefone/celular (61) 981391115 e/ou email: gabriela.a.g@outlook.com.br

\section{Endereço dos(as) responsável(eis) pela pesquisa (OBRIGATÓRIO):}

Instituição:

Endereço:

Bloco: /№: /Complemento:

Bairro: /CEP/Cidade:

Telefones p/contato: 


\section{ANEXO B}

\section{TERMO DE ASSENTIMENTO}

Título da pesquisa: Efetividade de um programa de exercícios preventivos para diminuição da incidência de lesões em atletas da Ginástica Artística Feminina.

Instituição do(a) ou dos(as) pesquisadores(as): Centro Universitário de Brasília

Pesquisadora responsável: Renata Elias Dantas

Pesquisadora assistente: Gabriela Aguiar Gengnagel

Você sabe o que é assentimento? Significa que você concorda com algo. No caso desse documento, significa que concorda em participar dessa pesquisa.

Antes de decidir se quer ou não participar, é importante que entenda o estudo que está sendo feito e o que ele envolverá para você.

Apresentamos esta pesquisa aos seus pais ou responsáveis e eles sabem que também estamos pedindo sua concordância. Se você deseja participar, seus pais ou responsáveis também terão que concordar. Mas você é livre para fazer parte ou não desta pesquisa, mesmo se seus pais ou responsáveis concordarem. Não tenha pressa de decidir.

Também poderá conversar com seus pais, amigos ou qualquer um com quem se sinta à vontade para decidir se quer participar ou não, e não é preciso decidir imediatamente.

Pode haver algumas palavras que não entenda ou situações que você queira que eu explique mais detalhadamente, porque ficou mais interessado(a) ou preocupado(a). Nesse caso, por favor, peça mais explicações.

\section{Natureza, objetivos e procedimentos do estudo}

O objetivo deste estudo é verificar se pode ocorrer uma diminuição de dores e lesões durante os treinos de ginástica após a implantação de um programa de exercícios preventivos.

Você vai passar por algumas avaliações para identificar a(as) lesão(ões) e em seguida vai passar um período fazendo determinados exercícios preventivos para a melhora dos seus treinos.

O que vai acontecer é: serão feitos alguns testes para avaliar sua força e sua flexibilidade, você já está acostumada a realizar os exercícios que serão aplicados, em seguida serão passados alguns exercícios preventivos para você realizar durante os treinos, os quais você também está acostumada a fazer. Algumas fotos serão tiradas enquanto você treina para os pesquisadores avaliarem se existe uma melhora ou não dos seus exercícios ginásticos.

Caso você se machuque durante a prática dos exercícios, a pesquisadora é apta para te levar ao hospital mais próximo do ginásio de treinamento, Hospital Regional da Asa Sul (HRAS), Rua SGAS, Quadras 608/609- módulo A, Brasília-DF.

Você não fará nada além do que estamos explicando neste documento.

A pesquisa será realizada no A pesquisa será realizada no Instituto Trata Joelho e Quadril (SGAS 915, Conjunto A/ Sala 359, Centro Clínico Advance Asa Sul. 


\section{Participação, recusa e direito de se retirar do estudo}

Sua participação poderá ajudar para que mais pessoas saibam mais sobre a melhora dos atletas de ginástica artística quando existe um programa de exercícios preventivos durante os treinos. Sua participação é voluntária, ou seja, você só participa se quiser e, de acordo com as leis brasileiras, não receberá dinheiro nem presentes pela sua participação neste estudo. Ninguém vai cobrar dinheiro de você ou de seus pais/responsável, ou vai tratá-la mal se não quiser participar.

Você poderá deixar a pesquisa a qualquer momento, bastando para isso falar com um dos pesquisadores responsáveis.

Conforme as normas brasileiras sobre pesquisa com a participação de seres humanos, você não receberá dinheiro nem presentes pela sua participação neste estudo.

\section{Confidencialidade}

Seus dados ficarão somente com os pesquisadores e não será permitido o acesso a out ras pessoas. O material com as suas informações (fichas e vídeos) ficarão guardados sob a responsabilidade de Gabriela Aguiar Gengnagel com a garantia de que ninguém vai falar de você para outras pessoas que não façam parte desta pesquisa e será queimado dentro de 4 anos.

Os resultados deste trabalho poderão ser apresentados em encontros ou revistas científicas. Entretanto, ele mostrará apenas os resultados obtidos como um todo, sem revelar seu nome, instituição a qual pertence ou qualquer informação que esteja relacionada com sua privacidade.

Caso ocorram danos causados pela pesquisa, todos os seus direitos serão respeitados de acordo com as leis do país. Os resultados estarão à sua disposição quando finalizada.

Se quiser falar algo ou tirar dúvida sobre como será/está sendo tratado na pesquisa, entre em contato com o Comitê de Ética em Pesquisa do Centro Universitário de Brasília CEP/UniCEUB, que aprovou esta pesquisa, pelo telefone 3966.1511 ou pelo e-mail cep.uniceub@uniceub.br. Também envie um e-mail ou ligue para informar se algo estiver errado durante a sua participação no estudo.

Este Termo Assentimento encontra-se impresso em duas vias, sendo que uma cópia será arquivada pelo(a) pesquisador(a) responsável, e a outra ficará com você.

\section{Assentimento}

$\mathrm{Eu}$, RG (se 
já tiver o documento), fui esclarecido(a) sobre a presente pesquisa, de maneira clara e detalhada. Fui informado(a) que posso solicitar novas informações a qualquer momento e que tenho liberdade de abandonar a pesquisa quando quiser, sem nenhum prejuízo para mim. Tendo o consentimento do meu(minha) responsável já assinado, eu concordo em participar dessa pesquisa. Os(As) pesquisadores(as) deram-me a oportunidade de ler e esclarecer as minhas dúvidas.

\section{Participante}

Pesquisador(a) responsável, telefone/celular ou e-mail

Pesquisador(a) assistente, telefone/celular ou e-mail 


\section{ANEXO C}

Termo de aceite institucional

Ao/À

Nome do responsável institucional

\section{Cargo}

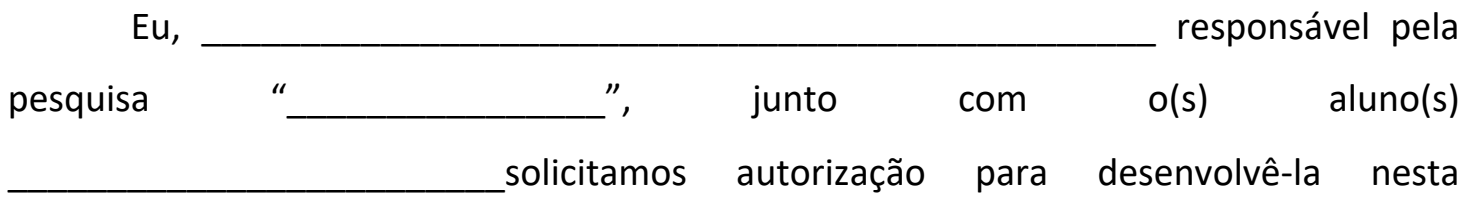

instituição, no período de . O estudo tem como objetivo(s) ; será realizado por meio dos seguintes procedimentos e terá participantes (identificar o número e o perfil dos participantes).

Declaro que a pesquisa ocorrerá em consonância com a Resolução n॰ 466/12 do Conselho Nacional de Saúde e suas complementares, que regulamentam as diretrizes éticas para as pesquisas que envolvem a participação de seres humanos, ressaltando que a coleta de dados e/ou informações somente será iniciada após a aprovação da pesquisa por parte do Comitê de Ética em Pesquisa do UniCEUB (CEP-UniCEUB) e da Comissão Nacional de Ética em Pesquisa (CONEP), se também houver necessidade.

Pesquisador responsável

Pesquisador assistente

O/A (chefe, coordenador/a, diretor/a) do/a (escola, academia, serviço, clínica, centro de saúde, hospital), (Dr/ạ. Prof/ạ. Diretor/a Nome do 
responsável) vem por meio desta informar que está ciente e de acordo com a realização da pesquisa nesta instituição, em conformidade com o exposto pelos pesquisadores.

Brasília-DF, de de

Nome e carimbo com o cargo do representante da instituição onde será realizado o projeto 
ANEXO D

NOME:

IDADE:

PESO:

ESTATURA:

Há quanto tempo sofreu a lesão? Precisou parar de treinar?

Histórico de lesões: Marque com "X" os pontos que você já sofreu algum tipo de lesão.
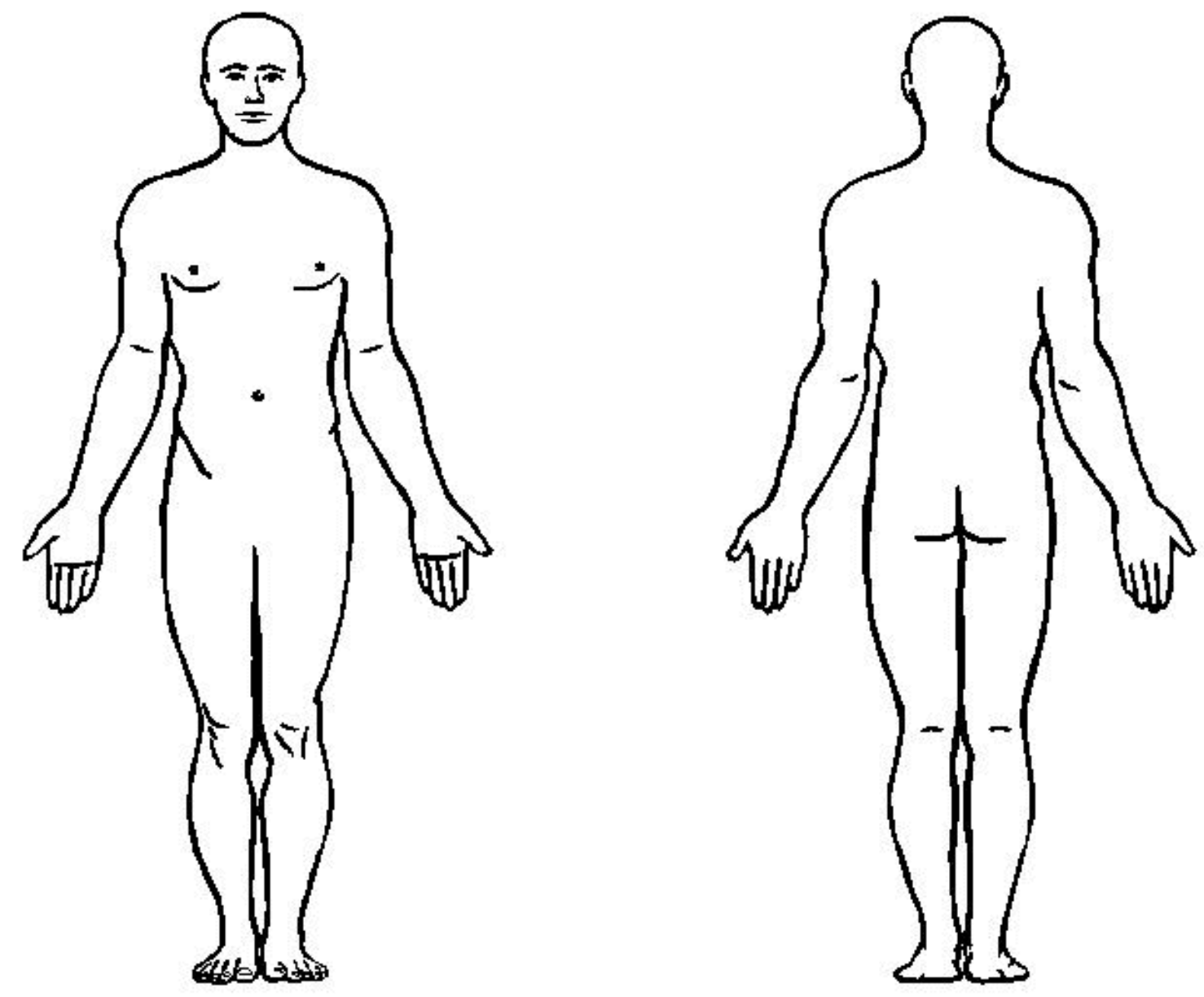